I.V. Bilynskyi, R.Ya. Leshko, H.Ya. Bandura

\title{
Influence of quantum dot shape on energy spectra of three- dimensional quantum dots superlattices
}

\author{
Drohobych Ivan Franko State Pedagogical University, Drohobych, Ukraine, leshkoroman@ gmail.com
}

\begin{abstract}
The superlattices of quantum dots InAs in a matrix $G a A s$ has been studied in this work. The superlattices of spherical and cubic quantum dots (QD) has been studied. Using the method of plane waves for different shapes of QT, analytical expressions for calculating the energy spectrum has been obtained. The dependences of energy zones at high symmetry dots has been constructed. Dependences of widths of zones has been found. It effects on the optical properties and, accordingly, the absorption and radiation coefficients. It has been shown that the largest bandwidth is for QD with the smallest symmetry (cubic quantum dots).
\end{abstract}

Keywords: superlattice, quantum dot, form of quantum dot, electron spectrum, zone width.

Received 25 October 2020; Accepted 15 December 2020.

\section{Introduction}

Quantum dot (QD) lasers based on the $\mathrm{A}_{\mathrm{III}} \mathrm{B}_{\mathrm{V}}$ compound, one of the large modern practical applications of quantum dots [1-3]. Theoretically, the expected benefits of such lasers (low limit current (about $\left.10 \mathrm{~A} / \mathrm{cm}^{2}\right)$ ), high gain, temperature stability of the limit current) have been tested. For telecommunications, the most desirable in practice is the range of maximum transparency of the fiber - wavelength $1.3-1.5 \mu \mathrm{m}$. It is at a wavelength of $1.3 \mu \mathrm{m}$ (that is, the maximum transparency of the optical fiber) that lasers are emitted and realized at quantum dots InAs in the matrix GaAs [45].

For further improvement of optoelectronic devices, it is necessary to conduct both experimental and theoretical studies of the physical properties of the structures of spatially ordered quantum dots. Therefore, the superlattice of quantum dots has attracted a lot of attention in recent years [6-10]. The authors of work [11] considered the superlattices of the cubic quantum dots GaAs/AlAs, which are widely used in infrared photodetectors. Using the approximation of the envelope function in the Kronig-Penney model, the authors showed that taking into account the overlap integrals with decreasing distances between QDs leads to the formation of three-dimensional minizones. However, the authors limited themselves to considering the energy spectrum of these electronic 3D-subbands, stating that it is more sensitive to the parameters of the superlattice of cubic quantum dots (SCQD) than to the shape of the QDs themselves. In work [12], the method of joined flat waves consists in calculating the electronic zone structure in the supergrate of spherical quantum dots (SSQD) in the approximation of effective masses. The influence of QDs size and the distance between them on the position of the energy bands and their width had investigated.

Studies have shown that the form of the QD significantly affects the energy spectrum of quasiparticles [13]. Experimental work shows a difference from spherical [14-16], which ultimately affects the optical properties of materials. However, most of the work is devoted to spherically symmetric QDs due to its simpler solution. Linear and nonlinear absorption coefficients at QDs of spherical shape had calculated in [17]. Attention was drawn to the ellipsoidal shape in relation to the more realistic comparison with the experimental size of QDs [15]. 


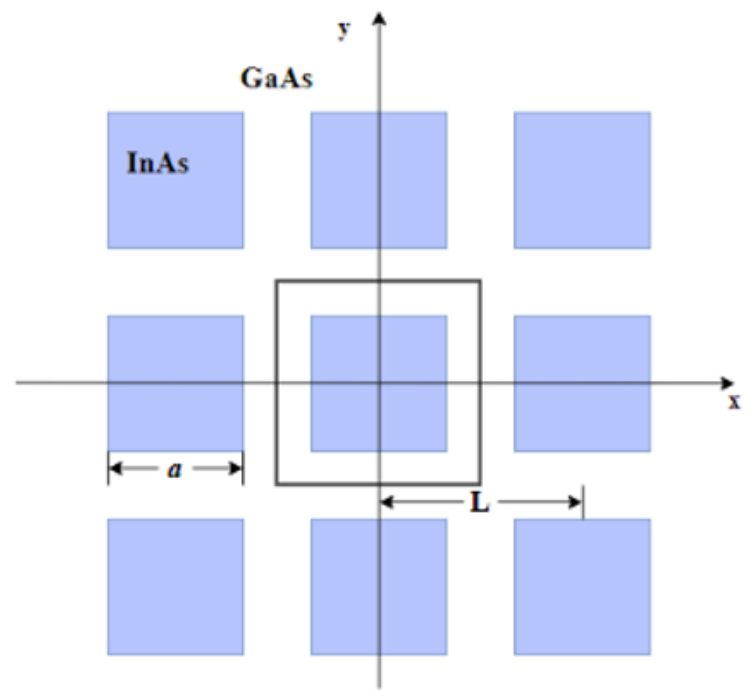

a)

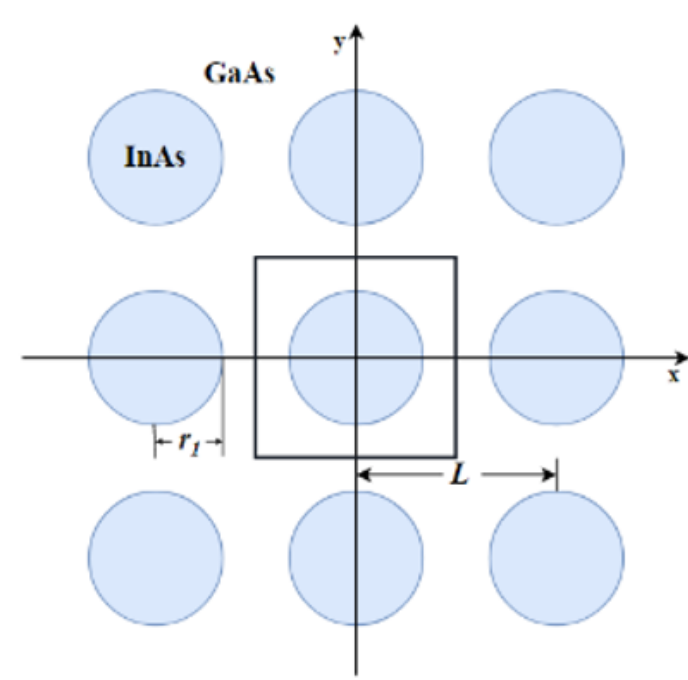

b)

Fig.1. Parameters of superlattices for a) cubic QDs; b) spherical QDs.

The blurring of the spectrum due to the heterogeneity of the shapes and sizes of QDs requires experimenters to create a uniform array of QDs. The high density of quantum dots can also lead to the formation of highwidth energy zones, which will increase the temperature dependence of laser radiation characteristics.

Therefore, it had the ordered arrays of quantum dots with small variance in size and shape that are important from the point of view of applied value. The aim of this work is to calculate the width of the electronic zone structure of an ordered array of spherical QDs using an example of a three-dimensional superlattice of nanocrystals InAs arranged in a GaAs medium of different shapes (spherical, cubic). In most cases, the shape of quantum dots grown in superlattices is uncertain. So our task is to study the effect of shape on the electron spectrum by the method of plane waves.

\section{Electron energies of semiconductor quantum dots}

Let as to consider the SSQD and SCQD InAs, placed in a matrix GaAs (Figure 1). Three-dimensional superlattices of quantum dots (cubic, spherical), which are located in the nodes of a cubic superlattice, the elementary cell of which is in the form of a cube, are investigated. We introduce the following notation: $r_{1}-$ radius of a spherical quantum dots (QD) in SSQD; $a-$ the length of the edge of the QD; $L$ - distance between centers of QD.

To find the energy spectrum and wave functions of an electron, we solve the electron Schrödinger equation:

$$
H_{e} \psi_{e}\left(r_{e}\right)=E \psi_{e}\left(r_{e}\right)
$$

with electron Hamiltonian:

$$
H_{e}=\mathbf{P} \frac{1}{2 m_{e}^{*}(x, y, z)} \mathbf{P}+V_{e}(x, y, z),
$$

where:

$$
\begin{aligned}
& V_{e}(x, y, z)=\left\{\begin{array}{l}
0, x^{2}+y^{2}+z^{2} \leq r_{1}^{2} \\
V_{0 e}, \text { others }
\end{array}\right. \\
& m_{e}^{*}=\left\{\begin{array}{l}
m_{1}, x^{2}+y^{2}+z^{2} \leq r_{1}^{2} \\
m_{2}, \text { others }
\end{array}\right.
\end{aligned}
$$

for SSQD and

$$
\begin{aligned}
& V_{e}(x, y, z)=\left\{\begin{array}{l}
0, \quad|x| \leq \frac{a}{2},|y| \leq \frac{a}{2},|z| \leq \frac{a}{2}, \\
V_{0 e}, \text { others, }
\end{array}\right. \\
& m_{e}^{*}= \begin{cases}m_{1}, & |x| \leq \frac{a}{2},|y| \leq \frac{a}{2},|z| \leq \frac{a}{2}, \\
m_{2}, & \text { others }\end{cases}
\end{aligned}
$$

for SCQD. $m_{1}$ and $m_{2}$ - effective electron masses in InAs and $G a A s$, accordingly.

The wave function of the electron $\psi_{e}\left(r_{e}\right)$ must gratify the periodicity condition. Let's write it in the form:

$$
\psi_{e}\left(r_{e}\right)=\frac{1}{(\sqrt{L})^{3}} \sum_{n_{x}, n_{y}, n_{z}} c_{n_{x}, n_{y}, n_{z}} e^{i\left(k_{n x} x+k_{n y} y+k_{n z} z\right)},
$$

where

$$
\begin{aligned}
& k_{n x}=k_{x}+n_{x} K, \quad k_{n y}=k_{y}+n_{y} K, \quad k_{n z}=k_{z}+n_{z} K, \\
& K=\frac{2 \pi}{L}, \quad \mathbf{k}\left(k_{x}, k_{y}, k_{z}\right), \quad n_{x}, n_{y}, n_{z}=0, \pm 1, \pm 2, \ldots
\end{aligned}
$$

When we put (2) and (3) in (1), multiplying from the 
left by $\frac{1}{(\sqrt{L})^{3}} e^{-i\left(k_{n x}^{\prime} x+k_{n y}^{\prime} y+k_{n z}^{\prime} z\right)}$ and integrate throughout

spherical QDs had gotten in the form of:

the region, the matrix elements of Hamiltonian (1) for

$$
-h^{2} c_{n_{x}, n_{y}, n_{z}}\left[\left(\frac{1}{2 m_{2}} \delta_{n_{x} n_{x}^{\prime}} \delta_{n_{y} n_{y}^{\prime}} \delta_{n_{z} n_{z}^{\prime}}+\frac{1}{2 m_{12} L^{3}} Q\right) \times\left(k_{n x} k_{n x}^{\prime}+k_{n y} k_{n y}^{\prime}+k_{n z} k_{n z}^{\prime}\right)+\left(\delta_{n_{x} n_{x}^{\prime}} \delta_{n_{y} n_{y}^{\prime}} \delta_{n_{z} n_{z}^{\prime}}-\frac{Q}{L^{3}}\right) \times V_{0 e}\right],
$$

for cubic QDs:

$$
-h^{2} c_{n_{x}, n_{y}, n_{z}}\left[\left(\frac{1}{2 m_{2}} \delta_{n_{x} n_{x}^{\prime}} \delta_{n_{y} n_{y}^{\prime}} \delta_{n_{z} n_{z}^{\prime}}+\frac{1}{2 m_{12} L^{3}} D_{i} D_{j} D_{k}\right) \times\left(k_{n x} k_{n x}^{\prime}+k_{n y} k_{n y}^{\prime}+k_{n z} k_{n z}^{\prime}\right)+\left(\delta_{n_{x} n_{x}^{\prime}} \delta_{n_{y} n_{y}^{\prime}} \delta_{n_{z} n_{z}^{\prime}}-\frac{D_{i} D_{j} D_{k}}{L^{3}}\right) \times V_{0 e}\right],
$$

where:

$$
\begin{aligned}
& \frac{1}{2 m_{12}}=\frac{1}{2 m_{1}}-\frac{1}{2 m_{2}}, \quad k_{n x}^{\prime}=k_{x}+n_{x}^{\prime} K, \quad k_{n y}^{\prime}=k_{y}+n_{y}^{\prime} K, \quad k_{n z}^{\prime}=k_{z}+n_{z}^{\prime} K, \\
& Q=\left\{\begin{array}{l}
\frac{4}{3} \pi r_{1}^{3}, n_{x}=n_{x}^{\prime}, n_{y}=n_{y}^{\prime}, n_{z}=n_{z}^{\prime}, \\
\frac{4 \pi\left(-r_{1} K \lambda \cos \left(r_{1} K \lambda\right)+\sin \left(r_{1} K \lambda\right)\right)}{(K \lambda)^{3}}, n_{x} \neq n_{x}^{\prime} \text { aбо } n_{y} \neq n_{y}^{\prime} \text { aбо } n_{z} \neq n_{z}^{\prime},
\end{array}\right. \\
& \lambda=\sqrt{\left(n_{x}-n_{x}^{\prime}\right)^{2}+\left(n_{y}-n_{y}^{\prime}\right)^{2}+\left(n_{z}-n_{z}^{\prime}\right)^{2}}, \quad s=(i, j, k) \\
& D_{s}=\left\{\begin{array}{l}
\frac{a}{L}, n_{x}=n_{x}^{\prime}, n_{y}=n_{y}^{\prime}, n_{z}=n_{z}^{\prime}, \\
\frac{\sin \left(\pi\left(n_{s}-n_{s}^{\prime}\right) \frac{a}{L}\right)}{\pi\left(n_{s}-n_{s}^{\prime}\right)}, n_{x} \neq n_{x}^{\prime}, \text { aбо } n_{y} \neq n_{y}^{\prime}, \text { або } n_{z} \neq n_{z}^{\prime},
\end{array}\right. \\
& \delta_{n_{q}, n_{q}^{\prime}}=\frac{1}{L} \sum_{n_{q}, n_{q}^{\prime}} \int_{-\frac{L}{2}}^{\frac{L}{2}} e^{i\left(k_{n q}-k_{n q}^{\prime}\right) q} d q, \quad q=(x, y, z) .
\end{aligned}
$$

Therefore, we can calculate the electron structures for given structures.

\section{Results}

Specific calculations had performed for heterosystem InAs/GaAs with the following parameters: $m_{1}=0.067$, $m_{2}=0.023, \quad V_{0 e}=0.77 e \mathrm{~V}$. In this paper we had used such a number of plane waves $n_{x}, n_{y}, n_{z}$ that provided accuracy in calculations with an error of $0.1 \%$.

To compare the effect of the shape of the QDs on the energy spectrum, the following two approximations were made: first, QDs have the same volumes, so the sizes are proportional; second, in all types of superlattices, the elementary cell is the same as the cube. The second approximation is equivalent to the fact that superlattices have the same density of QDs. To ensure the same volume based on a spherical QD with radius $r_{1}$. Figure 2 schematically shows QDs of different forms with the same volume.

Depending on the spherical QDs, the following parameters had selected for the cubic QDs:

$$
a=r_{1} \cdot \sqrt[3]{\frac{4}{3} \pi}
$$

Consider the electron energy spectrum in the cubic lattice of QDs (Fig. 3) with $k_{z}=0$. The figure shows that the qualitative dependence of the energy spectrum is the same.

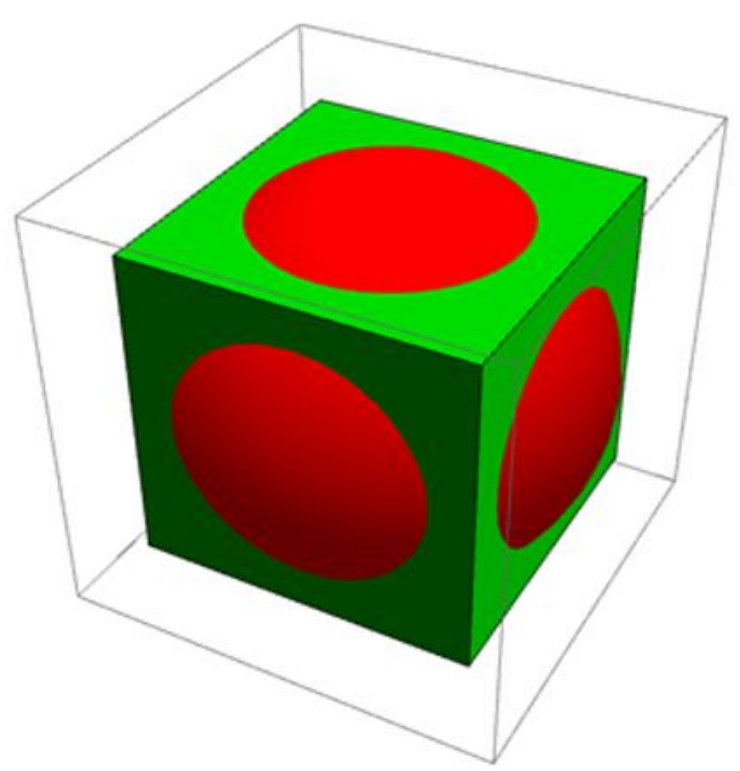

Fig. 2. Schematic representation of QDs of different forms of the same volume. 

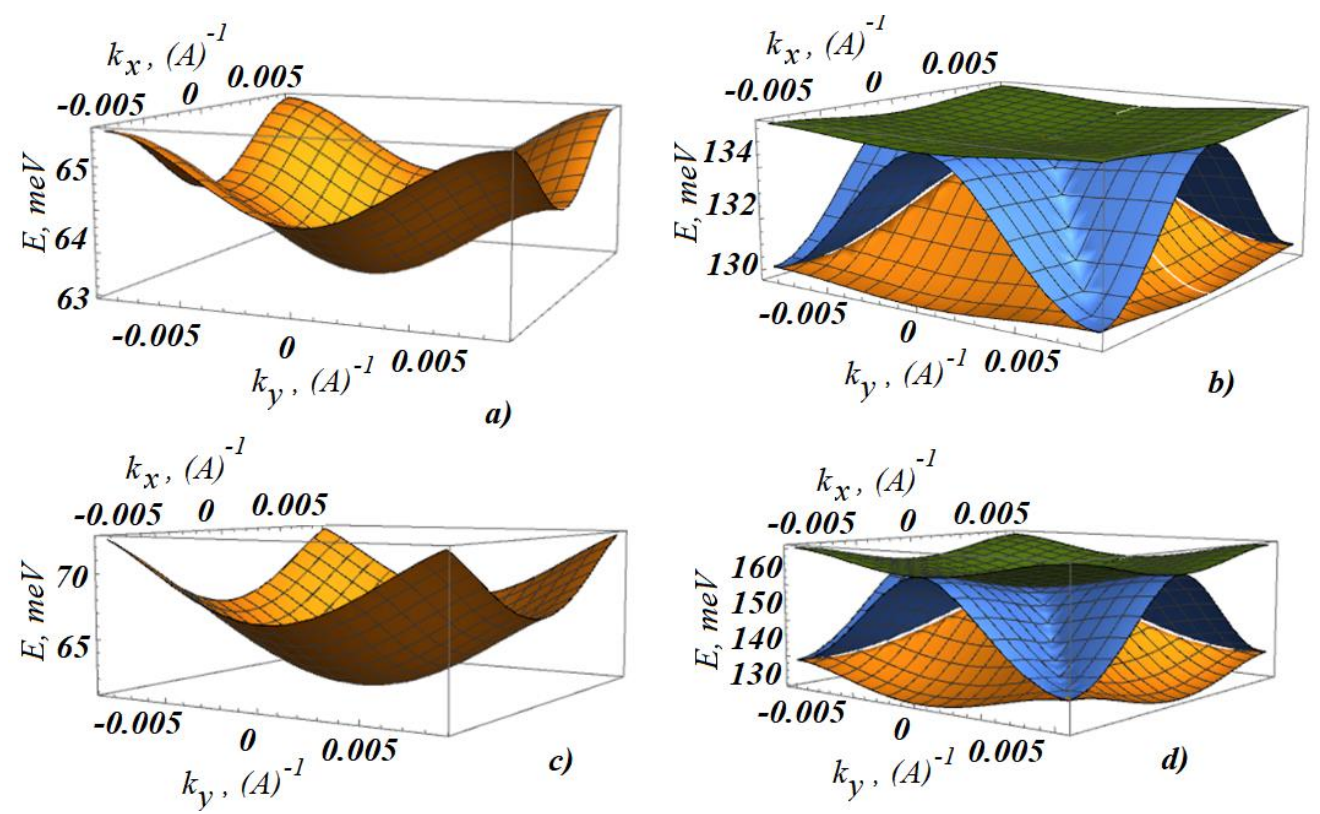

Fig. 3. The energy dependence of the first minizone of electron for a) SCQD; c) SSQD on the two-dimensional wave vector $\vec{k}\left(k_{x}, k_{y}, k_{z}=0\right)$. The energy dependence of the following minizones for b) SCQD; d) SSQD on the two-dimensional wave vector $\vec{k}\left(k_{x}, k_{y}, k_{z}=0\right)$, де $a=r_{1} \sqrt[3]{\frac{4 \pi}{3}}, \quad L=192 \dot{A}, \quad r_{1}=90 \dot{A}$.

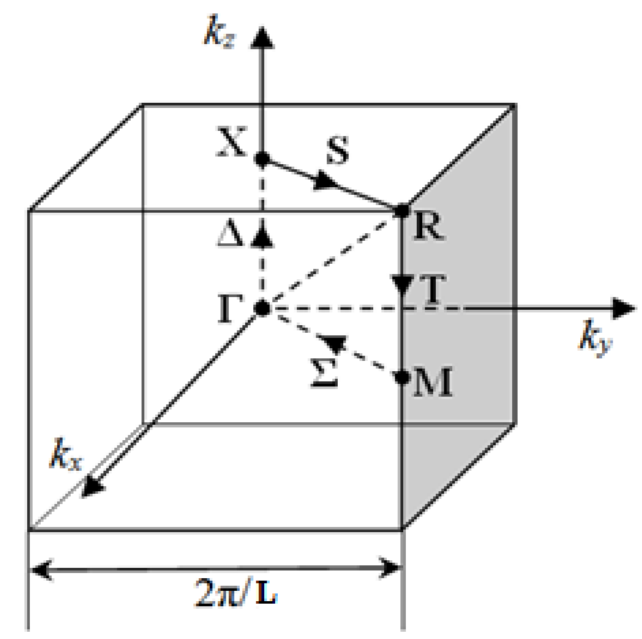

Fig. 4. Brillion zone of a three-dimensional superlattice of QDs.

For the convenience of energy spectrum analysis, we had used high symmetry dots of the k-space of the superlattice of quantum dots of cubic symmetry. It had shown on Figure 4. The high symmetry dots are as follows: $\quad \Gamma(0,0,0), \quad X\left(0,0, \frac{\pi}{L}\right), \quad M\left(\frac{\pi}{L}, \frac{\pi}{L}, 0\right)$, $R\left(\frac{\pi}{L}, \frac{\pi}{L}, \frac{\pi}{L}\right)$, and characteristic directions $\Delta\{\Gamma \rightarrow X\}, \quad S\{X \rightarrow R\}, \quad T\{R \rightarrow M\}$,
$\Sigma\{M \rightarrow \Gamma\}$

Figure 5 shows the electron spectra of four minizones for QDs of different shapes, calculated according to formulas (5) to (7) for the radius of the sphere.

The nature of the dependence of the energy spectrum is the same. The figure shows that the maximum energy of the first minizone had reached at $\mathrm{R}$, the minimum - at $\Gamma$. If we consider the II, III and IV minizones, then the maximum energy at $M$, the minimum at $X$. The graphs also show that zones II, III and IV are three times degenerate at $\mathrm{G}$ and $\mathrm{R}$. 
We have compared the widths of the zones of QD arrays formed by QD of different shapes (Figure 6). The graphs show that as the radius $R$ increases (i.e., as the volume of QD increases), the energy of all states decreases, regardless of the shape of the QD. This is due to the fact that the energy of the electron in the isolated QD decreases, the probability of the electron in the QD increases. Accordingly, the probability of tunneling the electron into other QDs decreases. In addition, it can be seen that the cubic QD has a wider zones width compared to the spherical QD. This is due to the fact that in cubic QD the electron has greater limitations in motion than in spherical QD.

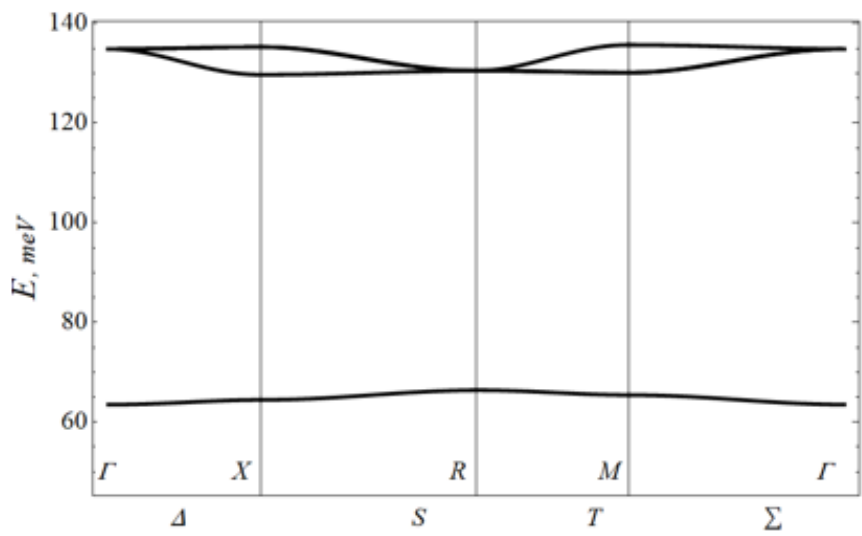

a)

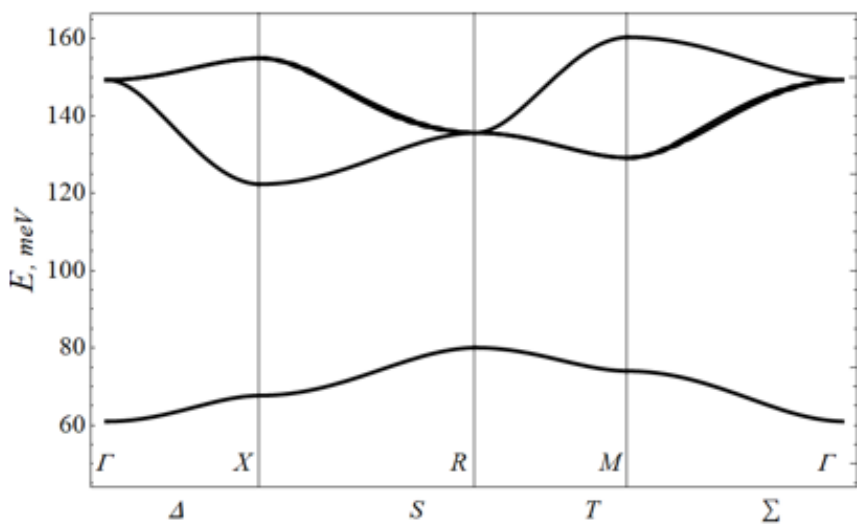

b)

Fig. 5. Electron energy spectra of the first and subsequent excited minizones of the superlattice of QDs for a) spherical QDs; b) cubic QDs, where $a=r_{1} \sqrt[3]{\frac{4 \pi}{3}}, \quad L=192 \dot{A}, \quad r_{1}=90 \dot{A}$.

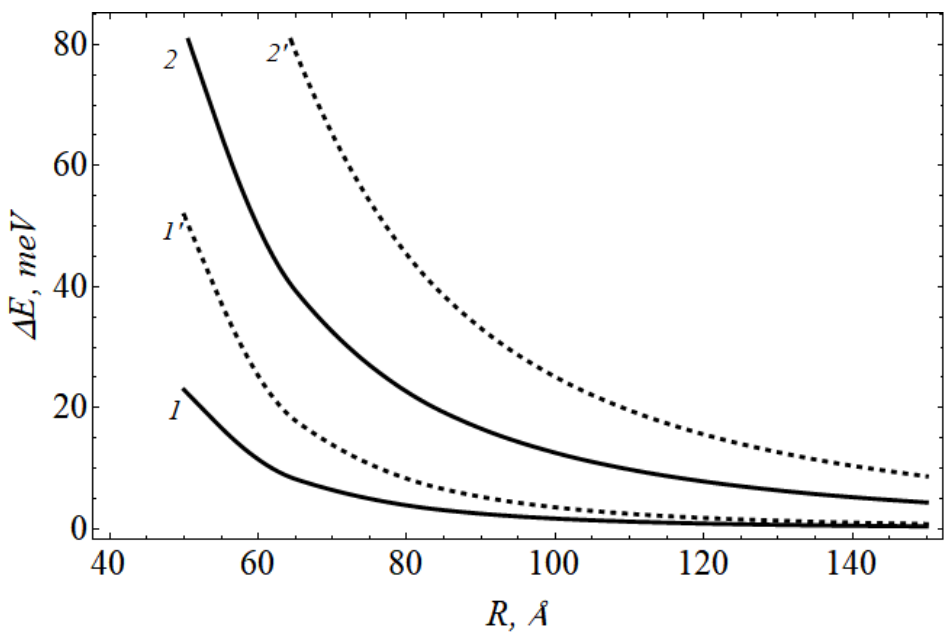

Fig. 6. Lattice width dependence on radius of spherical and cubic QDs. Solid line denotes the width of the first zone of the lattice $(1,2)$ and a dotted line - the second zone (1', 2'). 1,1'- zone widths for SSQD; 2,2'- zone widths for SCQD. 


\section{Conclusion}

In the paper had considered the three-dimensional superlattice of QDs InAs placed in the matrix GaAs. QDs had chosen of different forms: spheres, cubes, with the same volumes. Using the theory of plane waves, the energies of the ground and first excited states had calculated. Using high symmetry dots in the Brillion zone, the energy spectrum of the electron had calculated. And also the dependence of the widths of the zones of quantum dots of different forms had calculated, which will most likely affect the optical properties, namely the absorption and radiation coefficients. The proposed method of calculating the band spectra of QD superlattices can also be applied to cylindrical [18] QDs, hole states [19] taking into account heteroboundary stresses and polarization effects [20].

Bilynskyi I.V. - Doctor of Physical and Mathematical Sciences, Professor of Physics Department;

Leshko R.Ya. - Phd in of Physical and Mathematical Sciences, Docent of Physics Department;

Bandyra H.Ya. - master degree student of Physics and Mathematics Department.

[1] D.J. Mowbray and M.S. Skolnick, J. Phys. D: Appl. Phys. 38, 2059 (2005) (https://doi.org/10.1088/00223727/38/13/002).

[2] M. Sugawara, N. Hatori, M. Ishida, H. Ebe, Y. Arakawa, T. Akiyama, K.Otsubo, T. Yamamoto, and Y. Nakata, J. Phys. D: Appl. Phys. 38, 2126 (2005) (https://doi.org/10.1088/0022-3727/38/13/008).

[3] A. Moritz, R. Wirth, A. Hangleiter, A. Kurtenbach, and K. Eberl, Appl.Phys. Lett. 69, 212 (1996) (https://doi.org/10.1063/1.117375).

[4] N. Kirstaedter, N.N. Ledentsov, M. Grundmann, D. Bimberg, V.M. Ustinov, S.S. Ruvimov, M.V. Maximov, P.S. Kopev, Z.I. Alferov, U. Richter, P. Werner, U. Gosele, and J. Heydenreich, Electron. Lett. 30, 1416 (1994).

[5] J.P. Reithmaier, A. Somers, S. Deubert, R. Schwertberger, W. Kaiser, A. Forchel, M. Calligaro, P. Resneau, O. Parillaud, S. Bansropun, M. Krakowski, R. Alizon, D. Hadass, A. Bilenca, H. Dery, V. Mikhelashvilli, G. Eisenstein, M. Gioannini, I. Montrosset, T.W. Berg, M. van der Poel, J. Mørk, and B. Tromberg, J. Phys. D: Appl. Phys. 38, 2088 (2005).

[6] D. Pan, E. Towe, and S. Kennerly, Appl. Phys. Lett. 73, 1937 (1998) (https://doi.org/10.1063/1.122328).

[7] S. Maimon, E. Finkman, G. Bahir, S. E. Schacham, J. M. Garcia, and P.M. Petroff, Appl. Phys. Lett. 73, 2003 (1998) (https://doi.org/10.1063/1.122349).

[8] E.T. Kim, Z.H. Chen, and A. Madhukar, Appl. Phys. Lett. 79, 3341 (https://doi.org/10.1063/1.1417513).

[9] L. Fu, P. Lever, K. Sears, H.H. Tan, and C. Jagadish, IEEE Electron Device Lett. 26, 628 (2005).

[10] W. Zhang, H. Lim, M. Taguchi, S. Tsao, B. Movaghar, and M. Razeghi,Appl. Phys. Lett. 86, 191103 (2005) (https://doi.org/10.1063/1.1923176).

[11] M.R.K. Vahdani, G. Rezaei. Phys. Lett. A, 373, 3079 (2009) (https://doi.org/10.1016/j.physleta.2009.06.042).

[12] P. Bhattacharya, S. Ghosh, and A. D. Stiff-Roberts, Annu. Rev. Mater.Res. 34, 1 (2004).

[13] V.I. Boichuk, I.V. Bilynsky, I.O. Shakleina. Ukr. J. Phys. 53, 894 (2008).

[14] V.A. Gaisin, S.W. Karpov, E.V. Kolobkova, B.V. Novikov, V.D. Petrikov, A.A. Lipovsky, D.L. Fedorov, M.Ya.Yastrubova. Solid State Physics 41, 8 (1999).

[15] J.H. Blokland, M. Bozkurt, J.M. Ulloa, D. Reuter, A.D. Wieck, P.M. Koenraad, P.C.M. Christianen and J.C. Maan. Applied Physics Letters 94, 023107 (2009) (https://doi.org/10.1063/1.3072366).

[16] V. Kladko, M. Slobodian, P. Lytvyn, V. Strelchuk, Yu. Mazur, E. Marega, M. Hussein and G. Salamo. Phys. Status Solidi A 206, 1748 (2009) (https://doi.org/10.1002/pssa.200881593).

[17] Y. Yakar, B. Cakır, A. Ozmen. Optics Communications 283, $1795 \quad$ (2010) (https://doi.org/10.1016/j.optcom.2009.12.027).

[18] Shu-Shen Li, Jian-Bai Xia, Z.L. Yuan, Z.Y. Xu. China. Effective-mass theory for InAs/GaAs strained coupled quantum dots 912, 100083 (1996) (https://doi.org/10.1103/PhysRevB.54.11575).

[19] R.Ya. Leshko, I.V. Bilynskyi, Physica E: Low-dimentional Systems and Nanostructures 110, 10 (2019) (https://doi.org/10.1016/j.physe.2019.01.024).

[20] R.Ya. Leshko, I.V. Bilynskyi, Physica E: Low-dimentional Systems and Nanostructures 115, 113703 (2020) (https://doi.org/10.1016/j.physe.2019.113703). 


\section{I.В. Білинський, Р.Я. Лешко, Г.Я. Бандура}

\section{Вплив форми квантової точки на енергетичні спектри тримірних надграток квантових точок}

Дрогобицький державний педагогічний університет імені Івана Франка, м. Дрогобич, Украӥна, leshkoroman@gmail.com

Визначено зонний спектр надграток квантових точок різної форми у точках високої симетрії. Розглянуто кубічні, циліндричні та сферичні квантові точки. Обчислено ширини мінізон. Встановлено залежності мінізон від геометричних розмірів квантових точок та їх концентрації.

Ключові слова: надрешітка, квантова точка, форма квантової точки, електронний спектр, ширина зони. 